\title{
Collaboration between adult patients and practitioners when making decisions about prescribing opioid medicines for chronic non-cancer pain in primary care - A scoping review
}

\begin{tabular}{|c|c|}
\hline Journal: & British Journal of Pain \\
\hline Manuscript ID & BJP-20-0099.R2 \\
\hline Manuscript Type: & Original Manuscript \\
\hline Keywords: & Chronic Pain, Opioid, Interaction, Relationship, Patient \\
\hline Abstract: & $\begin{array}{l}\text { ABSTRACT } \\
\text { Background: Long-term opioid therapy ( }>\text { than } 12 \text { months) is not } \\
\text { effective for improving chronic non-cancer pain and function. Where } \\
\text { patients are not experiencing pain relief with long-term opioids, the } \\
\text { opioid should be tapered and discontinuation considered. Practitioners } \\
\text { may find it challenging to tell patients experiencing pain that they are } \\
\text { better off reducing or not taking medicines that do not help. This review } \\
\text { aims to ascertain what is published about: (1) the interaction and (2) the } \\
\text { nature of the relationship between practitioners and patients when } \\
\text { prescribing opioids for chronic non-cancer pain in primary care. } \\
\text { Method: A scoping review of English language qualitative, quantitative or } \\
\text { mixed method studies in databases including: MEDLINE, Embase, } \\
\text { PsycINFO, AMED, BNI, CINALH EMCARE and HMIC. The identified papers } \\
\text { were reviewed to provide a descriptive summary of the literature. } \\
\text { Results: The review identified } 20 \text { studies. The studies used a range of } \\
\text { methods including interviews, focus groups, audio and video recordings } \\
\text { of clinical consultations, telephone survey and data from patient records. } \\
\text { One study reported that researchers had engaged with a patient } \\
\text { advisory group to guide their research. } \\
\text { Patients expressed the importance of being treated as individuals, not } \\
\text { being judged and being involved in prescribing decisions. Practitioners } \\
\text { expressed difficulty in managing patient expectations and establishing } \\
\text { trust. Opioid risk and practitioner suspicion shape opioid prescribing } \\
\text { decisions. } \\
\text { There is a paucity of literature about how precisely practitioners } \\
\text { overcome interactional challenges and implement personalised care in } \\
\text { practice. } \\
\text { Conclusion: The studies in this review ascertain that practitioners and } \\
\text { patients often find it challenging to achieve shared decisions in opioid } \\
\text { review consultations. Effective communication is essential to achieving } \\
\text { good clinical practice. Collaborative research with PPI partners should be } \\
\text { aimed at identifying communication practices that support practitioners } \\
\text { to achieve shared decisions with patients when reviewing opioids for } \\
\text { chronic non-cancer pain. }\end{array}$ \\
\hline
\end{tabular}

\section{SCHOLARONE"
Manuscripts}




\begin{abstract}
Background: Long-term opioid therapy (> than 12 months) is not effective for improving chronic non-cancer pain and function. Where patients are not experiencing pain relief with long-term opioids, the opioid should be tapered and discontinuation considered. Practitioners may find it challenging to tell patients experiencing pain that they are better off reducing or not taking medicines that do not help. This review aims to ascertain what is published about: (1) the interaction and (2) the nature of the relationship between practitioners and patients when prescribing opioids for chronic non-cancer pain in primary care.
\end{abstract}

Method: A scoping review of English language qualitative, quantitative or mixed method studies in databases including: MEDLINE, Embase, PsycINFO, AMED, BNI, CINALH EMCARE and HMIC. The identified papers were reviewed to provide a descriptive summary of the literature.

Results: The review identified 20 studies. The studies used a range of methods including interviews, focus groups, audio and video recordings of clinical consultations, telephone survey and data from patient records. One study reported that researchers had engaged with a patient advisory group to guide their research.

Patients expressed the importance of being treated as individuals, not being judged and being involved in prescribing decisions. Practitioners expressed difficulty in managing patient expectations and establishing trust. Opioid risk and practitioner suspicion shape opioid prescribing decisions.

There is a paucity of literature about how precisely practitioners overcome interactional challenges and implement personalised care in practice.

Conclusion: The studies in this review ascertain that practitioners and patients often find it challenging to achieve shared decisions in opioid review consultations. Effective communication is essential to achieving good clinical practice. Collaborative research with PPI partners should be aimed at identifying communication practices that support practitioners to achieve shared decisions with patients when reviewing opioids for chronic non-cancer pain. 


\section{INTRODUCTION}

Chronic non-cancer pain (CNCP) lasts more than three months and includes numerous pain conditions: lower back pain, musculoskeletal pain, abdominal pain, headache and neuropathic pain 1 .

The prevalence of CNCP in UK adults varies from $35 \%$ to $50 \%$ with moderately severe pain and disabling pain prevalence being $10 \%$ to $14 \%^{2}$. Back pain alone accounts for $40 \%$ of sickness absences in the $\mathrm{NHS}^{3}$. Patients with CNCP consult their GPs up to five times more frequently than other patients ${ }^{4}$ and chronic pain is the presenting condition in around a fifth of primary care consultations ${ }^{4}$.

\section{Long-term opioid medicines}

Opioids are effective analgesics for acute pain and pain at the end of life but there is limited evidence supporting long-term prescribing to manage $\mathrm{CNCP}^{5}$. The risks of long-term use may outweigh any benefits. A review of the effectiveness and risks of long-term opioid prescribing (> 3 months) did not find any studies comparing opioid versus placebo or nonopioid therapy researching outcomes beyond 12 months ${ }^{6}$. It concluded that there was insufficient evidence to determine the effectiveness of long-term opioid therapy for improving CNCP and function. It also highlighted that dose dependent risks are associated with the use of long-term opioids including overdose, opioid abuse and fractures ${ }^{6}$. Further to this, a pragmatic randomised trial comparing opioid versus non-opioid medicines; found opioids were not superior to treatment with non-opioids for improving pain-related function over 12 months ${ }^{7}$. In an epidemiological study comparing patients using opioids and non-opioids for CNCP, long-term use of opioids was significantly associated with reporting of moderate to severe pain, poor self-rated health, higher use of the health care system, and a negative influence on quality of life ${ }^{8}$. The cross-sectional nature of this study means that causal relationships cannot be drawn. However, it is important to note that long-term opioid treatment did not meet any of the key outcomes related to successfully treating CNCP. 


\section{Opioid prescribing trends}

The majority of prescribing opioid medicines in the UK takes place in primary care through General Practices (GPs). Despite the lack of research evidence for the effectiveness of longterm opioids in the management of CNCP, an analysis of prescribing data shows a substantial increase in prescribing practice between 1998 and 2016 . In 2016, 776 opioid prescriptions were dispensed per 1000 patients $^{9}$. A longitudinal analysis (between 2005 and 2012) of prescribing opioids in general practice showed the number of patients prescribed a weak opioid at least once almost doubled from $6.5 \%$ to $12.4 \%{ }^{10}$ and the number of patients prescribed a strong opioid at least once increased by more than six fold from $0.13 \%$ to $0.85 \%^{10}$.

In relation to the duration for which opioids are being prescribed, between 2005 and 2012 approximately $5 \%$ of patients per GP practice were being prescribed a long-term opioid and $1 \%$ of patients were being prescribed a long-term strong opioid ${ }^{10}$. These findings were echoed in a population based study of 49,999 patients using the Clinical Practice Research Datalink ${ }^{11}$. This study showed that in $2014,5.2 \%$ of the study population were prescribed opioids and about $34 \%$ of opioid patients were receiving a prescription for more than 30 days duration ${ }^{11}$. More recently Ashye and colleagues reported that about $40 \%$ of the 703 participants in their study received more than 3 opioid prescriptions a year ${ }^{12}$.

\section{National guidance}

The National Institute of Health and Care Excellence (NICE) and the Faculty of Pain Medicine (FPM) recommend that where patients are not experiencing relief from pain with long-term opioid medicines they should be encouraged and supported to reduce and stop the opioid if possible ${ }^{13,14}$. Practitioners may find it challenging to discuss with patients experiencing intolerable pain that they are better off reducing or not taking medicines that do not help, particularly if there is no therapeutic alternative ${ }^{15}$. The aims of this review are to ascertain what is published about: (1) the interaction and (2) the nature of the relationship between practitioners and patients when prescribing opioids for CNCP in primary care. 


\section{METHODS}

\section{Review design}

This review takes the form of a scoping review. It follows guidance set out in the Joanna Briggs Institute $(\mathrm{JBI})$ manual for reviewers ${ }^{16}$ and is reported using the PRISMA preferred reporting items for systematic reviews and meta-analyses extension for scoping reviews checklist ${ }^{45}$. We developed and agreed a predefined protocol for conducting this review (Appendix 1).

\section{Inclusion criteria}

Target population

Adults over the age of 18 years prescribed an opioid for CNCP.

Context of the study

Decision making when prescribing opioids for CNCP can be influenced by factors relating to the patient, the consultation, experiences and perceptions of the patient and prescriber as well as the healthcare system in which the prescribing takes place. This scoping review will focus on prescribing by any healthcare practitioner (doctor, pharmacist, nurse) in a primary care setting.

Phenomena of interest

Studies were included if they document the interaction and relationship between practitioners and patients relating to prescribing opioids for CNCP.

\section{Types of studies}

Studies published in English language using qualitative, mixed-method or quantitative methods were included. Systematic reviews and meta-synthesis were also included. Reference lists of identified systematic reviews were reviewed for studies that may not have been highlighted in the initial search. Conference abstracts or presentations, thesis and dissertations were excluded due to the amount of detail that is usual to these texts (e.g. restricted word count associated with abstracts and substantial word count associated with thesis and dissertations). 


\section{Search strategy}

Initially a search was conducted on Embase to help identify and refine search terms. Search terms from known existing literature were used to help support this process. A full search using the identified terms was conducted using MEDLINE, Embase, PsycINFO, AMED, BNI, CINALH EMCARE and HMIC. All databases were searched from inception. The search was completed on $11^{\text {th }}$ June 2020. The full search strategy is detailed in Appendix 2.

\section{Data collection}

The studies identified for inclusion were reviewed independently by two reviewers at each stage of the review process: title screening, abstract screening and full paper review. Reviewers recorded their decisions. Discrepancies between reviewers were documented and discussed with the review team so that an outcome could be achieved.

\section{Assessment of included studies}

The JBI reviewer's manual recommends that scoping reviews should aim to provide an overview of the existing evidence regardless of quality ${ }^{16}$. Individual studies were therefore not methodologically assessed for quality. A charting table was developed to record the relevant information from each study, this included: author(s), publication year, country where the study was conducted, aims and objectives of the study, the population being studied, sample size (if applicable), methodology / design / methods and findings related to the scoping review question. This was done iteratively with the review team giving feedback on the data charted so as to provide a logical and descriptive summary of the included studies that aligns with the aims of the scoping review. 


\section{RESULTS}

Twenty studies were included in the review. A flow diagram illustrating the number of studies that were included and excluded at each stage is in figure 1.

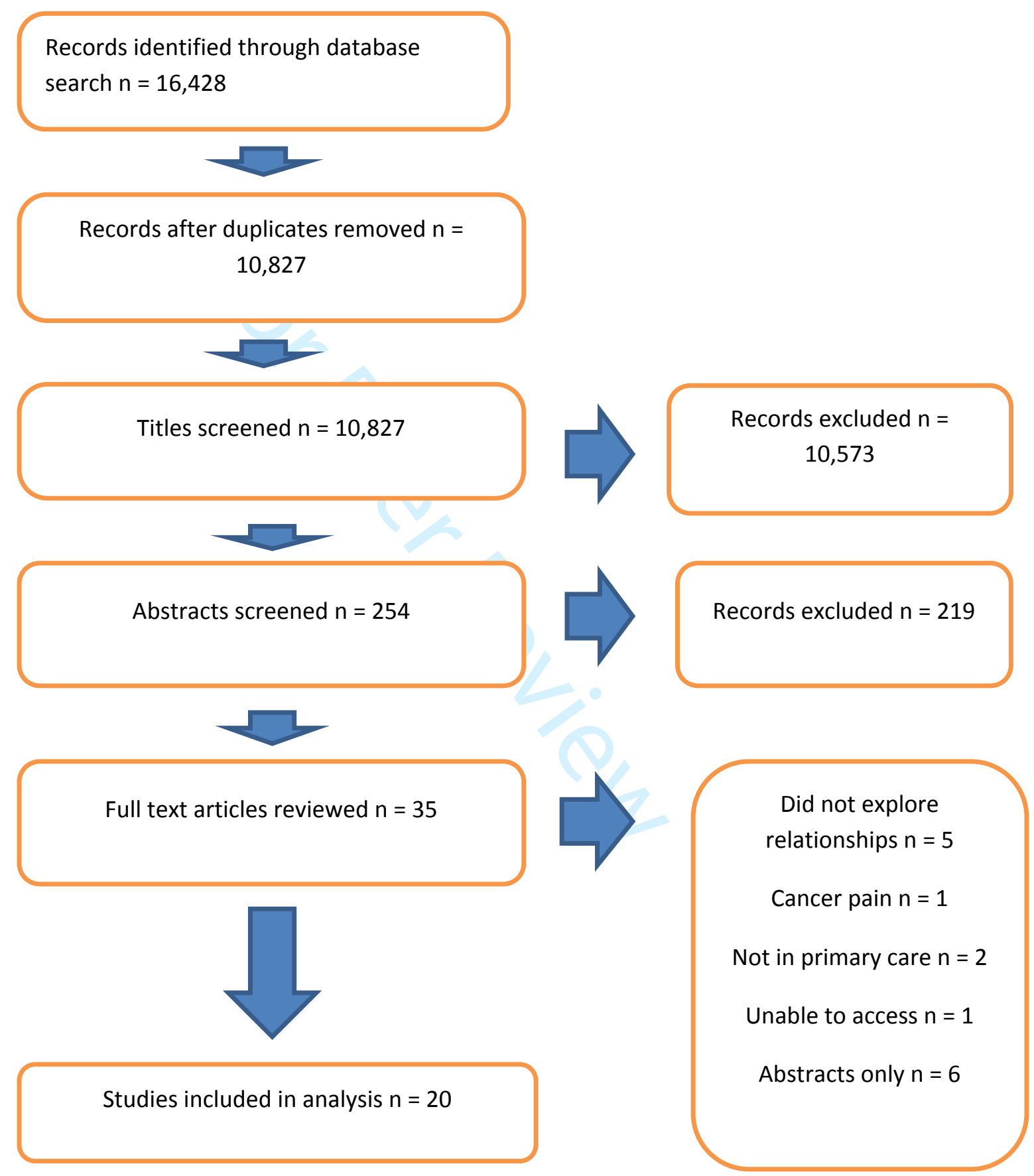

Figure 1: PRISMA flow diagram illustrating the search strategy results 


\section{Description of the included studies}

All of the studies included involved patients and practitioners prescribed or prescribing opioids for CNCP in primary care. Sixteen studies were undertaken in the United States of America (USA) 17-32, two were performed in the United Kingdom (UK ${ }^{33,34}$ and one was based in Canada ${ }^{35}$.

One of the included studies is a meta-synthesis ${ }^{36}$. Some of the studies included in the metasynthesis ${ }^{17-20,22,33}$ are also included in this review. The rationale for including the metasynthesis in this review is to incorporate the authors' theorised perspective of the practitioner-patient relationship.

One study reported that researchers had engaged with a patient advisory group to guide their research ${ }^{28}$.

A descriptive summary of the studies and the key findings related to the review aims is presented in Appendix 3.

\section{Aims of the studies in the review}

Three studies aimed to understand patient perspectives / experience of opioid prescribing 21,26,27. Practitioner perspectives / experience of opioid prescribing, was the aim of three further studies ${ }^{22,29,35}$ as well as the meta-synthesis ${ }^{36}$. Both patient and practitioner perspectives / experience of opioid prescribing was the aim in two studies ${ }^{17,18}$.

Two studies explored practitioner and patient trust when prescribing opioids ${ }^{19,28}$, whilst a further four studies explored understanding communication between practitioners and patients $20,24,30,31$. Three studies examined the decision making process $23,25,32$.

One study aimed to understand how problematic long-term opioid prescribing becomes established ${ }^{33}$ and another assessed the acceptability of a pain review service ${ }^{34}$.

\section{$\underline{\text { Population studied }}$}

All of the studies included patients and practitioners with an experience of prescribed opioids for CNCP. CNCP included all non-cancer pain, however in six of the studies this was limited to musculoskeletal pain $20,23-25,30,31$. Three studies included practitioners that were from several disciplines (doctors, nurses, clinical pharmacists) $22,29,34$. 


\section{Methods for data collection}

The included studies used a range of methods to explore the practitioner and patient relationship. Six of the studies used interviews ${ }^{17,18,22,26,34,35}$ and five of the studies used both interviews and focus groups ${ }^{19,21,27,29,33}$. Six studies used recordings of clinical consultations, with four using an audio recording $20,23,25,30$ and two using video recording ${ }^{24,31}$. One study collected data from reviewing patient records ${ }^{32}$ and one study used a telephone survey of patients ${ }^{28}$.

\section{Methods for data analysis}

The studies using data from interviews and focus groups used a variety of methods for data analysis. Thematic analysis ${ }^{17,22,27,34}$ or grounded theory ${ }^{19,21,33}$ were the most used approaches. The theoretical domains framework ${ }^{35}$, immersion and crystalisation ${ }^{18}$, mixed deductive and inductive ${ }^{26,29}$ approaches were also used by researchers. Thematic analysis was also used to analyse data in the one study reviewing medical records ${ }^{32}$. Those studies using audio or video recordings to collect data used immersion and crystalisation ${ }^{20}$ and constant comparison ${ }^{25,30}$ as qualitative approaches to analyse data. However quantitative approaches using statistical analysis of coded data were also used in four studies ${ }^{23,24,28,31}$. One study used a list of coded communication measures to relate practitioner and patient characteristics to communication ${ }^{23}$, whilst another study coded data from videotaped practitioner and patient consultations and then related these codes to the patient and practitioner experience of the consultation ${ }^{24}$. A further study used coded assessments of patient statements. Assessments were coded as positive, negative or ambivalent and were compared with practitioner responses to these statements ${ }^{31}$. In the study using a telephone survey, the researchers provided raw counts for responses to questions about trust, such as "I feel my doctor trusts me in how I manage my opioid pain medicine". Results were adjusted for potential bias due to non-respondents ${ }^{28}$. 


\section{Findings related to the review question}

Interaction between practitioners and patients when making decisions about prescribed opioids for CNCP

Discussions about opioids were directed by pressure from guidance 25,27 , greater patient pain catastrophisation $^{23}$ or where practitioners were orientated towards psychosocial interventions ${ }^{23}$. Practitioner and patient disagreement ${ }^{25,33,36,32}$ along with requests for an increase in opioid dose were associated with significantly worse experience of consultations $^{24}$. Negative interactions happen where decisions were taken unilaterally by the practitioner $27,30,32$, or where the stigma associated with prescribing opioids resulted in a reluctance to prescribe and interrogation of the patient ${ }^{18,19,21}$. Some patients prescribed opioids describe not being treated as individuals ${ }^{17}$, being judged ${ }^{18,21,26}$ and not feeling that they are involved in the decision making process ${ }^{25,30,34}$. Patients valued the importance of being listened to $20,25,34$ especially where practitioners have taken the time to build a supportive relationship with the patient ${ }^{22,27,34}$ and where they experience a degree of interpersonal assurance ${ }^{19}$.

Nature of the relationship between patients and practitioners when prescribing opioids for CNCP

Establishing mutual trust lays the foundation to successful pain management ${ }^{17}$. One study reported a high degree of trust between practitioners and patients ${ }^{28}$. However, others reported that practitioners find it difficult to establish trust with patients when there is a difference in understanding of pain ${ }^{18,33}$ or if they are uncertain about the patients' account of pain ${ }^{19,29}$. The subjective nature of pain alongside inconsistencies between diagnosis and the patients' experience contribute to compromising trust ${ }^{22}$. This may lead to practitioners forming fixed negative attitudes towards patients ${ }^{33}$ and miss opportunities where review of opioids can be explored ${ }^{31}$.

Practitioners report difficulty in managing patient expectation ${ }^{22}$, experiencing stress and reduced job satisfaction as a result of challenging conversations about opioids ${ }^{22,29,35}$. When prescribing opioids there is a tension between managing pain and facilitating opioid misuse ${ }^{35}$ as well as a tension between keeping the patient satisfied and safe use of prescribed opioids $^{25,29}$. This can compromise the therapeutic alliance. A systematic meta-synthesis of practitioner perceptions theorised that opioid risk and practitioner suspicion shape opioid prescribing decisions ${ }^{36}$. 


\section{Gaps in evidence}

The studies exploring communication $20,24,30,31$ or decision making $23,25,32$ between practitioners and patients used audio recording of clinical consultations ${ }^{20,23,25,30}$, video recording of clinical consultations ${ }^{24,31}$ and review of patient clinical records ${ }^{32}$ to conduct their research.

Data was analysed qualitatively in four studies $20,25,30,32$. Whilst this design gives practitioner and patient insights into communicative practice and decision making in clinical practice, it misses how utterances and non-verbal cues from practitioners impact on the patient in real time $^{37}$ and hence misses precisely how practitioners achieve collaboration with patients in clinical consultations.

Video recording of clinical consultations captures both verbal and non-verbal communicative clues $^{38}$ to identify important insights about clinical practice ${ }^{38}$. Of the two studies that used this method, both used associations between coded data and interactional behaviours to identify communicative practice ${ }^{24,31}$. Coding relies on the researchers' preconceived theoretical concept of the consultation, this may uncover key aspects of communicative practice in consultations, but may also miss new or relevant interactional practice ${ }^{39,40}$ that practitioners use to achieve collaboration with patients.

\section{DISCUSSION}

This review identifies that practitioners and patients face interactional challenges when making decisions about prescribing long-term opioids for CNCP. This can compromise the therapeutic alliance in a clinical relationship.

Medicines optimisation (MO) ensures patients get the right choice of medicine, at the right time, and are engaged in the process by practitioners ${ }^{41}$. MO should follow the principles of shared decision making where patients are empowered to be involved in decisions about their health. Individuals and clinicians should work together to understand the treatment options that are most appropriate, bearing in mind the person's individual circumstances ${ }^{42}$.

Effective practitioner-patient communication is a central clinical function in building a therapeutic relationship ${ }^{43}$. The importance of communication has been highlighted in practice guidelines. The role of effective communication in improving patient care is underlined by the Personalised Care Institute ${ }^{44}$. It has also highlighted in NICE and FPM guidance for assessing and managing pain ${ }^{13,14}$. A review of clinician and patient communication identified improved practitioner-patient communication tends to increase patient involvement in managing their condition; influence patient satisfaction, adherence, and health care utilization; and improve quality of care and health outcomes ${ }^{43}$. 
One study in this review reported on Patient and Public Involvement (PPI) to guide research about trust between practitioner and patient when prescribing opioids for $\mathrm{CNCP}^{28}$. Patient partners as lived experience based experts contribute knowledge that is complementary to that of researchers and professionals. Their input into the design, conduct and dissemination of research has been shown to improve the quality, relevance and uptake of research ${ }^{46}$. The National Institute for Health Research recommends that PPI input should be embedded in practice so that researchers naturally take on the values and practices of effective public involvement ${ }^{47}$.

This review ascertains that there is a paucity of literature about how precisely practitioners overcome interactional challenges that might present when reviewing opioids and implement personalised care in practice. It also highlights a lack of published research conducted with PPI partners. Further collaborative study of practitioner and patient interaction using methods such as conversation analysis, which analyse the structure of communication, will provide new insights into how communication is co-constructed between practitioner and patient ${ }^{40}$. This can then be used to identify communicative practice that help enact trust, achieve therapeutic alliance and give an insight into what good communicative practice looks like in routine primary care encounters ${ }^{37,40}$.

\section{Strengths and weakness}

This study was conducted in line with the JBI guidelines following a systematic process. A predefined review protocol was agreed prior to commencement. Two reviewers independently assessed studies at each stage of the process. Data extraction was completed using a standardised spread-sheet by the lead reviewer. An independent patient and public involvement partner, with lived experience of CNCP has reviewed this paper and suggested comments on the findings.

Studies may have been missed due to the search terms used in the review. The studies included have not been assessed for quality and reflect a high degree of heterogeneity with regard to method and theoretical stance. The majority of studies are based in the USA. This may present a bias as the interaction and nature of relationship between practitioners and patients will reflect the health system within which they operate. This review intends to make comment on the state of current literature on the interaction between practitioners and patients when prescribing opioids for CNCP and identify gaps for further research. 


\section{Recommendations}

- Researchers with PPI partners should consider a systematic review of literature to identify communication practices that support collaborative care with patients prescribed opioids for CNCP.

- Researchers with PPI partners should consider further examination of video recorded clinical consultations and identify communication practices that support collaborative care with patients prescribed opioids for CNCP.

- A consensus process is needed to depict best practice and provide guidance on communication practices that help support collaborative care with patients prescribed opioids for CNCP.

\section{CONCLUSION}

The studies in this review ascertain that practitioners and patients often find it challenging to achieve shared decisions in opioid review consultations. Effective communication is essential to achieving good clinical practice. Collaborative research with PPI partners should be aimed at identifying communication practices that support practitioners to achieve personalised care with patients when reviewing opioids for CNCP. 


\section{DECLARATIONS AND ACKNOWLEDGEMENTS}

Patient and Public Involvement: We would like to thank Lynn Laidlaw for reviewing this paper and providing comments on the findings.

Funding: No funding was received to support this study.

Conflicts of interest: All authors declare that they have no conflicts of interest in relation to this paper.

Ethical approvals: No ethical approval was required for this scoping review.

\section{FIGURE AND APPENDIX}

Figure 1: PRISMA flow diagram illustrating the search strategy results

Appendix 1: Protocol for this systematic scoping review

Appendix 2: Search strategy adopted in this systematic scoping review

Appendix 3: Chart describing study characteristics 


\section{REFERENCES}

1. Faculty of Pain Medicine. Opioids aware, about pain. Accessed: 4th July 2020. Available at: https://www.fpm.ac.uk/opioids-aware-understanding-pain-medicinespain/about-pain.

2. Fayaz A. Croft P. Langford R. Donaldson L. Jones G. Prevalence of chronic pain in the UK: a systematic review and meta-analysis of population studies BMJ Open 2016;6:e010364.

3. British Pain Society. Press Release: Chronic Pain Costs the UK £Billions but Research Funding Is Inadequate. Accessed: 4th June 2020. Available at: https://www.britishpainsociety.org/mediacentre/news/british-pain-society-pressrelease-chronic-pain-costs-the-uk-billions-but-research-funding-is-inadequate/.

4. Royal College of General Practitioners. Chronic pain. Accessed: $4^{\text {th }}$ July 2020. Available at: https://www.rcgp.org.uk/clinical-and-research/resources/a-to-z-clinicalresources/chronic-pain.aspx.

5. Faculty of Pain Medicine. Opioids aware, long-term prescribing. Accessed: $10^{\text {th }}$ April 2021. Available at: Opioids Aware | Faculty of Pain Medicine (fpm.ac.uk).

6. Chou R. Turner J. Devine E. Hansen R. Sullivan S. Blazina I. Dana T. Bougatsos C. Deyo R. The Effectiveness and Risks of Long-Term Opioid Therapy for Chronic Pain: A Systematic Review for a National Institutes of Health Pathways to Prevention Workshop. Annals of Internal Medicine 2015;162:276-282.

7. Krebs E. Gravely A. Nugent S. Jensen A. DeRonne B. Goldsmith E. Kroenke K. Bair M. Noorbaloochi S. Effect of Opioid vs Nonopioid Medications on Pain-Related Function in Patients With Chronic Back Pain or Hip or Knee Osteoarthritis Pain: The SPACE Randomized Clinical Trial. JAMA 2018;319(9):872-882.

8. Eriksen J, Sjøgren P, Bruera E, Ekholm O, Rasmussen NK. Critical issues on opioids in chronic non-cancer pain: An epidemiological study. Pain 2006;125(1):172-179.

9. Curtis H. Croker R. Walker A. Richards G. Quinlan J. Goldacre B. Opioid prescribing trends and geographical variation in England, 1998-2018: a retrospective database study. The Lancet Psychiatry 2019;6(2):140-150. 
10. Foy R. Leaman B. McCrorie C. Petty D. House A. Bennett M. Carder P. Faulkner S. Glidewell L. West R. Prescribed opioids in primary care: cross-sectional and longitudinal analyses of influence of patient and practice characteristics BMJ Open 2016;6:e010276.

11. Public Health Research Consortium. Prescribing patterns in dependence forming medicines 2017. Accessed: 3rd July 2020. Available at: https://www.natcen.ac.uk/media/1800571/Trends-in-long-term-prescribing-ofdependence-forming-medicines.pdf.

12. Ashaye T. Hounsome N. Carnes D. Taylor S. Homer K. Eldridge S. Spencer A. Rahman A. Foell J. Underwood M. Opioid prescribing for chronic musculoskeletal pain in UK primary care: results from a cohort analysis of the COPERS trial. BMJ Open 2018;8(6):e019491.

13. Faculty of Pain Medicine. Opioids aware, long-term prescribing. Accessed: $4^{\text {th }}$ July 2020. Available at: https://www.fpm.ac.uk/opioids-aware-structured-approach-opioidprescribing/long-term-prescribing.

14. National Institute of Health and Care Excellence. Chronic pain (Primary and Secondary) in over 16s: assessment of all chronic pain and management of primary chronic pain 2021. Accessed: 10th April 2021. Available at: https://www.nice.org.uk/.

15. Stannard, C. Opioids in the UK: what's the problem? BMJ 2013; 347:f5108.

16. Joanna Briggs Institute Reviewers Manual 2019. Accessed: 10th June 2020. Available at: https://wiki.joannabriggs.org/display/MANUAL/Chapter+11\%3A+Scoping+reviews.

17. Bergman A. Matthias M. Coffing J. Krebs E. Contrasting tensions between patients and PCPs in chronic pain management: A qualitative study. Pain Medicine 2013;14(11):1689-1697.

18. Esquibel, A. Borkan, J. Doctors and patients in pain: Conflict and collaboration in opioid prescription in primary care. Pain 2014;155(12):2575-2582.

19. Buchman D. Ho A. Illes J. You present like a drug addict: Patient and clinician perspectives on trust and trustworthiness in chronic pain management. Pain Medicine 2016;17(8):1394-1406. 
20. Matthias, M. Krebs E. Bergman A. Coffin, J. Bair, M. Communicating about opioids for chronic pain: a qualitative study of patient attributions and the influence of the patient-physician relationship. European Journal of Pain 2013;18(6):835-843.

21. Wallace L. Wexler R. McDougle L. Miser W. Haddox J. Voices that may not otherwise be heard: A qualitative exploration into the perspectives of primary care patients living with chronic pain. Journal of Pain Research 2014;7:291-299.

22. Matthias, M. Parpart, A. Nyland, K. Huffman, M. Stubbs, D. Sargent, C. Bair, M. The patient-provider relationship in chronic pain care: providers' perspectives. Pain Medicine 2010;11(11):1688-1697.

23. Shields C. Fuzzell L. Christ S. Matthias M. Patient and provider characteristics associated with communication about opioids: An observational study. Patient Education and Counselling 2019;102(5):888-894.

24. Henry S. Bell R. Fenton J. Kravitz R. Communication about chronic pain and opioids in primary care: impact on patient and physician visit experience. Pain 2018;159(2):371-379.

25. Matthias, M. Talib, T. Huffman, M. Managing Chronic Pain in an Opioid Crisis: What Is the Role of Shared Decision-Making? Health Communication 2019;35(10):12391247.

26. Frank J. Levy C. Matlock D. Calcaterra S. Mueller S. Koester S. Binswanger I. Patients' Perspectives on Tapering of Chronic Opioid Therapy: A Qualitative Study. Pain Medicine 2016;17(10):1838-1847.

27. Henry S. Paterniti D. Feng B. Losif A. Kravitz R. Weinberg G. Cowan P. Verba S. Patients' Experience With Opioid Tapering: A Conceptual Model With Recommendations for Clinicians. Journal of Pain 2018;20(2):181-191.

28. Sherman K. Walker R. Saunders K. Shortreed S. Parchman M. Hansen R. Thakral M. Ludman E. Dublin S. Von Korff M. Doctor-patient trust among chronic pain patients on chronic opioid therapy after opioid risk reduction initiatives: A survey. Journal American Board Family Medicine 2018;31(4):578-587.

29. Kennedy L. Binswanger I. Mueller S. Levy C. Matlock D. Calcaterra S. Koester S. Frank J. "Those conversations in my experience don't go well": A qualitative study of primary care provider experiences tapering long-term opioid medications. Pain Medicine 2018;19(11):2201-2211. 
30. Matthias M. Johnson N. Shields C. Bair, M. Mackie, P. Huffman, M. Alexander, S. "I'm Not Gonna Pull the Rug out From Under You". Patient-Provider Communication about Opioid Tapering. The Journal of Pain 2017;18(11):1365-1373.

31. Henry S. Gosdin M. White, A. Kravitz R. "It Sometimes Doesn't Even Work": Patient Opioid Assessments as Clues to Therapeutic Flexibility in Primary Care. Journal of General Internal Medicine 2020;35(6):1635-1640.

32. Buonora M. Perez H. Stumph J. Allen R. Nahvi, S. Cunningham C. Merlin J. Starrels J. Medical Record Documentation About Opioid Tapering: Examining Benefit-toHarm Framework and Patient Engagement. Pain Medicine 2020;21(10):1-9.

33. McCrorie C. Closs S. House A. Petty, D. Ziegler L. Glidewell, L. West, R. Foy, R. Understanding long-term opioid prescribing for non-cancer pain in primary care: a qualitative study. BMC Family Practice 2015;16:121-129.

34. Kesten J. Thomas K. Scott L. Bache K. Hickman M. Campbell R. Pickering A. Redwood S. Acceptability of a primary care-based opioid and pain review service: a mixed-methods evaluation in England. British Journal of General Practice 2020; 70 (691): e120-e129.

35. Desveaux L. Saragosa M. Kithulegoda N. Ivers N. Understanding the behavioural determinants of opioid prescribing among family physicians: A qualitative study. BMC Family Practice 2019;20(1)59.

36. Kennedy M. Pallotti P. Dickinson R. Harley C. 'If you can't see a dilemma in this situation you should probably regard it as a warning': a metasynthesis and theoretical modelling of general practitioners' opioid prescription experiences in primary care," British Journal of Pain 2019;13(3):159-176.

37. Maynard D, Heritage J. Conversation analysis, doctor patient interaction and medical communication. Medical Education 2005;39(4):428-435.

38. Parry R. Pino M. Faull C. Feathers L. Acceptability and design of video based research on healthcare communication: Evidence and recommendations. Patient Education and Counselling 2016;99(8):1271-1284.

39. Psathas G. Reflections on the History of Ethnomethodology: The Boston and Manchester "Schools". The American Sociologist 2008;39(1):38-67. 
40. Barnes R. Conversation Analysis of Communication in Medical Care: Description and Beyond, Research on Language and Social Interaction 2019;52(3):300-315.

41. National Institute of Health and Clinical Excellence. Medicines Optimisation: the safe and effective use of medicines to enable the best possible outcomes 2015. Accessed: 10th July 2020. Available at: https://www.nice.org.uk.

42. National Health Service England. Shared Decision Making Programme 2018. Accessed: 5th July 2020. Available at: https://www.england.nhs.uk/rightcare/shareddecision-making/.

43. Ha JF, Longnecker N. Doctor-patient communication: a review. Ochsner J. 2010;10(1):38-43.

44. NHS England Personalised Care Institute. Accessed $1^{\text {st }}$ February 2021. Available at NHS England »Personalised Care Institute

45. Preferred reporting items for Systematic Reviews and Meta-analyses extension for Scoping Reviews (PRISMA-ScR) Checklist. Accessed: $1^{\text {st }}$ July 2020. Available at: http://prisma-statement.org/.

46. Boivin, A. Richards, T. Forsythe, L. Grégoire, A. L’Espérance, A. Abelson, J. Kristin, , C. Evaluating patient and public involvement in research BMJ 2018; 363 :k5147.

47. National Institute for Health Research. Going the Extra Mile: Improving the nation's health through public involvement in research 2015. Accessed: $1^{\text {st }}$ February 2021. Available at: www.nihr.ac.uk. 


\section{APPENDIX 1}

\section{SCOPING REVIEW PROTOCOL}

Collaboration between practitioners and patients when making decisions about prescribing opioids for chronic non-cancer pain in primary care - A scoping review

$\underline{\text { Aim }}$

- To identify what research literature exists on the contexts of the interaction between patients and practitioners and factors that influence opioid use and prescribing.

- To identify what research literature exists on the nature of the relationship between patients and practitioners when prescribing opioid medicines.

Types of studies to be included:

- Research papers that document the relationship between practitioners and patients relating to prescribing opioid medicines for chronic non-cancer pain in a primary care setting

- Research papers published in a peer-reviewed journal

- Research papers using a quantitative, qualitative or mixed-method approach

Exclusion criteria

Non-English language papers, policy documents, ${ }_{2}$ conference abstracts or presentations and study protocols will be excluded.

Search strategy

Databases to be searched

MEDLINE, Embase, PsycINFO, AMED, BNI, CINALH EMCARE, HMIC from imception

\section{Search terms}

(((exp CONVERSATION/ OR exp "PROFESSIONAL-PATIENT RELATIONSHIP"/ OR exp "PATIENT ATTITUDE"/ OR exp "HEALTH PERSONNEL ATTITUDE"/ OR exp "GENERAL PRACTICE"/ OR "Primary care"/ OR (communication*).ti.ab OR (patient*).ti,ab OR (attitude ${ }^{*}$ ).ti,ab OR (interaction*).ti,ab OR (relationship*).ti,ab OR (communication*) ti.ab OR (primary healthcare).ti,ab OR (GP*).ti,ab OR (physician*).ti,ab OR (doctor*).ti,ab OR (clinician*).ti,ab OR (practitioner $\left.^{*}\right)$.ti,ab OR (pharmacist*).ti.ab OR (nurse $\left.{ }^{\star}\right)$.ti.ab

AND

((chronic pain).ti,ab OR exp "CHRONIC PAIN"/ OR (chronic non-cancer pain).ti,ab OR (chronic non cancer pain).ti,ab))

AND

((tramadol).ti,ab OR (hydromorphone).ti,ab OR (fentanyl).ti.ab OR (pethidine).ti,ab OR (dihydrocodeine).ti,ab OR (oxycodone).ti,ab OR (hydrocodone).ti,ab OR (oxymorphone).ti,ab OR (morphine).ti,ab OR (codeine).ti,ab OR (meptazinol).ti,ab OR (buprenorphine).ti,ab OR (diamorphine).ti.ab. OR (dipipanone).ti.ab OR (meperidine).ti.ab. OR (papaveretum).ti.ab. 
OR (opiate*).ti,ab OR (opioid*).ti,ab OR exp "NARCOTIC ANALGESIC AGENT"/ OR exp "MORPHINE DERIVATIVE"/))

[English language] [Human age groups Adult 18 to 64 years OR Aged 65+ years]

\section{Study selection}

Following removal of duplicate citations, retrieved titles and abstracts will be screened for inclusion by two reviewers working independently, and disagreements will be resolved by discussion with the wider scoping review team.

Data extraction

A charting table or form will be developed to record the key information of the source, this will include:

- Author(s)

- Year of publication

- Origin/country of origin (where the study was published or conducted)

- Aims/purpose

- Study population and sample size (if applicable)

- Methodology / Design / Methods

- Key findings

- How findings relate to the scoping review question/s.

This process will provide a logical and descriptive summary of the results that aligns with the objective/s and question/s of the scoping review

A reviewer will chart each study, the charting process will be an iterative process, and it may become apparent that additional unforeseen data can be usefully charted. The review team will feedback on charting of two or three studies to ensure all relevant results are extracted.

\section{Presentation of the results}

The results of a scoping review will be presented as a chart of the data extracted from the included papers and in a descriptive format that aligns with the aims / objectives and scope of the review. 


\title{
APPENDIX 2
}

\section{Search strategy}

\section{Databases to be searched}

MEDLINE, Embase, PsycINFO, AMED, BNI, CINALH EMCARE, HMIC from imception

\section{Search terms}

(((exp CONVERSATION/ OR exp "PROFESSIONAL-PATIENT RELATIONSHIP"/ OR exp "PATIENT ATTITUDE"/ OR exp "HEALTH PERSONNEL ATTITUDE"/ OR exp "GENERAL PRACTICE"/ OR "Primary care"/ OR (communication*).ti.ab OR (patient $^{*}$ ).ti,ab OR (attitude*).ti,ab OR (interaction*).ti,ab OR (relationship*).ti,ab OR

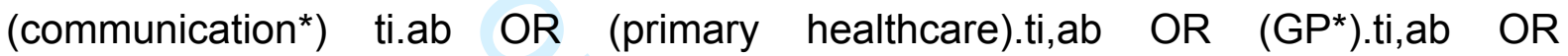
(physician*).ti,ab OR (doctor*).ti,ab OR (clinician*).ti,ab OR (practitioner* $\left.{ }^{*}\right) . t i, a b$ OR (pharmacist $\left.^{*}\right)$.ti.ab OR (nurse $\left.{ }^{*}\right) \cdot$ ti.ab

AND

((chronic pain).ti,ab OR exp "CHRONIC PAIN"/ OR (chronic non-cancer pain).ti,ab OR (chronic non cancer pain).ti,ab))

\begin{abstract}
AND
((tramadol).ti,ab OR (hydromorphone).ti,ab OR (fentanyl).ti.ab OR (pethidine).ti,ab OR (dihydrocodeine).ti,ab OR (oxycodone).ti,ab OR (hydrocodone).ti,ab OR (oxymorphone).ti,ab OR (morphine).ti,ab OR (codeine).ti,ab OR (meptazinol).ti,ab OR (buprenorphine).ti,ab OR (diamorphine).ti.ab. OR (dipipanone).ti.ab OR (meperidine).ti.ab. OR (papaveretum).ti.ab. OR (opiate*).ti,ab OR (opioid*).ti,ab OR exp "NARCOTIC ANALGESIC AGENT"/ OR exp "MORPHINE DERIVATIVE"/))
\end{abstract}

[English language] [Human age groups Adult 18 to 64 years OR Aged 65+ years] 


\section{APPENDIX 3}

\section{Chart describing study characteristics}

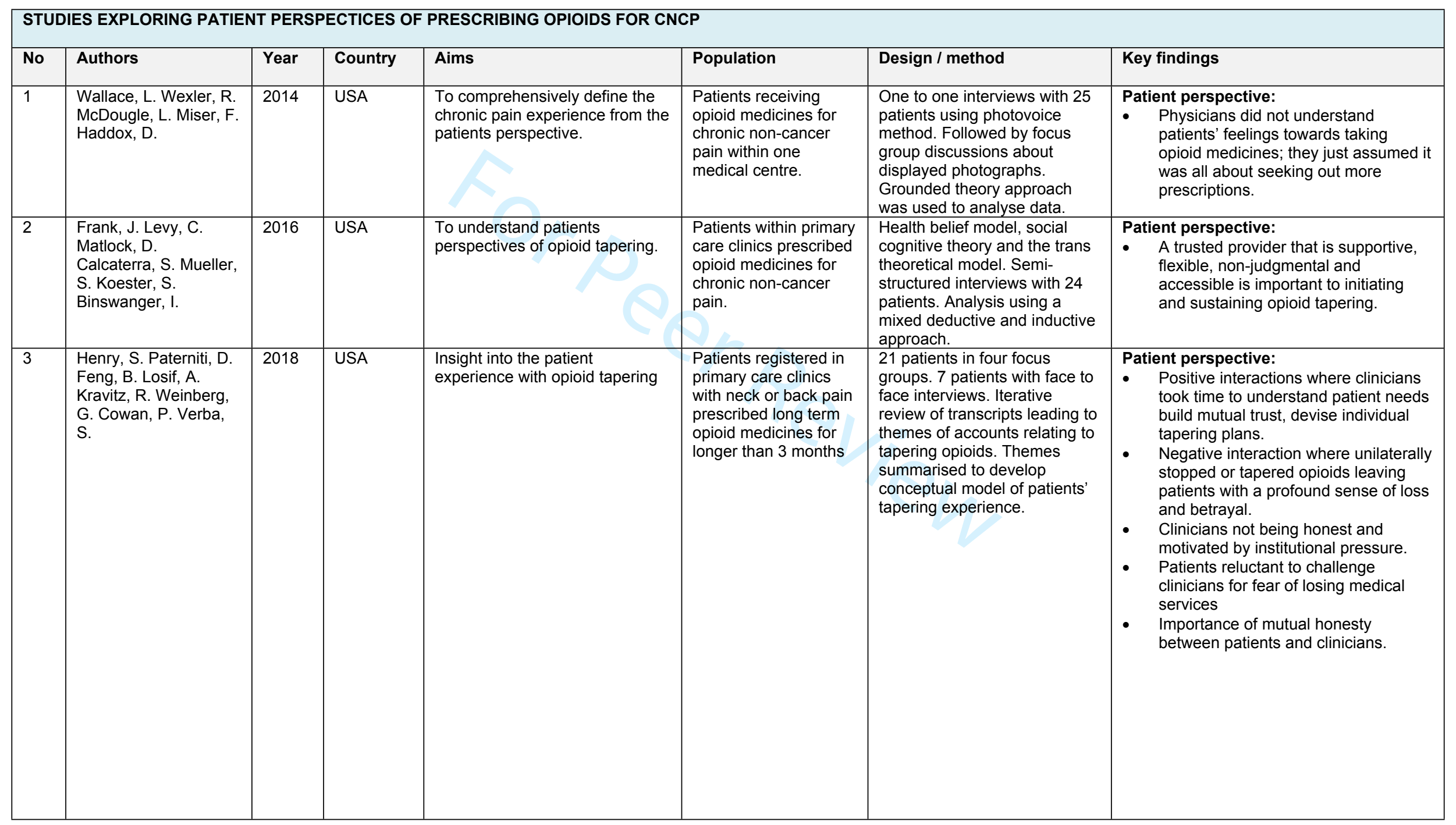




\begin{tabular}{|c|c|c|c|c|c|c|c|}
\hline \multicolumn{8}{|c|}{ STUDIES EXPLORING PRACTITIONER PERSPECTIVES OF PRESCRIBING OPIOIDS FOR CNCP } \\
\hline No & Authors & Year & Country & Aims & Population & Design / method & Key findings \\
\hline 4 & $\begin{array}{l}\text { Matthias, M. Parpart, } \\
\text { A. Nyland, K. } \\
\text { Huffman, M. Stubbs, } \\
\text { D. Sargent, C. Bair, M. }\end{array}$ & 2010 & USA & $\begin{array}{l}\text { To understand primary care } \\
\text { provider perspectives of chronic } \\
\text { pain }\end{array}$ & $\begin{array}{l}\text { Primary care clinic } \\
\text { providers. } \\
\text { Multidisciplinary. }\end{array}$ & $\begin{array}{l}\text { In-depth semi-structured } \\
\text { interviews with } 20 \text { primary } \\
\text { care providers. Thematic } \\
\text { analysis of data. }\end{array}$ & $\begin{array}{l}\text { Practitioner perspective: } \\
\text { - } \quad \text { Developing strong relationships with } \\
\text { patients enhances trust. } \\
\text { - } \quad \text { Difficulties in managing patient } \\
\text { expectation, especially when } \\
\text { prescribing opioids. } \\
\text { - Subjective nature of pain, } \\
\text { inconsistencies between diagnostic } \\
\text { test and patient account leading to } \\
\text { mistrust } \\
\text { Stress, lack of satisfaction and } \\
\text { hostility encountered with some } \\
\text { patients. }\end{array}$ \\
\hline 5 & $\begin{array}{l}\text { Kennedy, L. } \\
\text { Binswanger, I. } \\
\text { Mueller, S, Levy, C. } \\
\text { Matlock, D. } \\
\text { Calcaterra, S. Koester, } \\
\text { S. Frank, J. }\end{array}$ & 2018 & USA & $\begin{array}{l}\text { Explore primary care providers' } \\
\text { experience of discussing and } \\
\text { implementing opioid tapering } \\
\text { with patients on long term opioid } \\
\text { therapy. }\end{array}$ & $\begin{array}{l}\text { Primary care providers } \\
\text { (multidisciplinary) with } \\
\text { experience of } \\
\text { prescribing or } \\
\text { monitoring opioid for } \\
\text { chronic pain }\end{array}$ & $\begin{array}{l}\text { Forty primary care providers } \\
\text { participated in six semi- } \\
\text { structured interviews and } \\
\text { focus groups. Data was } \\
\text { analysed using a mixed } \\
\text { inductive - deductive } \\
\text { approach. }\end{array}$ & $\begin{array}{l}\text { Practitioner perspective: } \\
\text { - } \quad \text { Discussions of opioid tapering } \\
\text { emotionally charged and exhausting. } \\
\text { - Trust compromised when uncertain } \\
\text { about patient account and when } \\
\text { enforced tapering } \\
\text { - Conflict between keeping patients } \\
\text { satisfied and safely prescribing opioid } \\
\text { medicines. }\end{array}$ \\
\hline 6 & $\begin{array}{l}\text { Desveaux, L. } \\
\text { Saragosa, M. } \\
\text { Kithulegoda, N. Ivers, } \\
\text { M. }\end{array}$ & 2019 & Canada & $\begin{array}{l}\text { Understand current perspectives } \\
\text { of family practitioners to opioid } \\
\text { prescribing and the perceived } \\
\text { barriers and enablers to } \\
\text { guideline adherent prescribing }\end{array}$ & Family practitioners & $\begin{array}{l}\text { Theoretical domains } \\
\text { framework. Semi-structured } \\
\text { interviews with } 22 \\
\text { practitioners. Data coded to } \\
\text { construct a matrix of how } \\
\text { individual belief interacts with } \\
\text { behavioural determinants of } \\
\text { prescribing opioid medicines. }\end{array}$ & $\begin{array}{l}\text { Practitioner perspective: } \\
\text { - Challenging conversations around } \\
\text { opioid prescribing threaten } \\
\text { therapeutic relationships. } \\
\text { - Emotional consequences of } \\
\text { prescribing led to some practitioners } \\
\text { avoiding prescribing altogether. } \\
\text { Tension between managing pain and } \\
\text { facilitation opioid misuse. }\end{array}$ \\
\hline 7 & $\begin{array}{l}\text { Kennedy, M. Pallotti, } \\
\text { P. Dickinson, R. } \\
\text { Harley, C. }\end{array}$ & 2019 & $\begin{array}{l}\text { USA }-9 \\
\text { UK }-3 \\
\text { Canada - } \\
1\end{array}$ & $\begin{array}{l}\text { Identify and synthesise } \\
\text { qualitative literature describing } \\
\text { the factors influencing the nature } \\
\text { and extent of opioid prescribing } \\
\text { by GPs for patients with chronic } \\
\text { non cancer pain in primary care. }\end{array}$ & GPs in primary care & $\begin{array}{l}\text { Systematic synthesis of } 13 \\
\text { qualitative studies }\end{array}$ & $\begin{array}{l}\text { Practitioner perspective: } \\
\text { - Factors relating to the specific patient, } \\
\text { the consultation, experiences and } \\
\text { perceptions of the prescriber will } \\
\text { influence opioid prescribing decisions. } \\
\text { A theoretical framework proposing } \\
\text { that risk, disagreement and suspicion } \\
\text { axes interact to shape opioid } \\
\text { prescribing decisions. }\end{array}$ \\
\hline
\end{tabular}




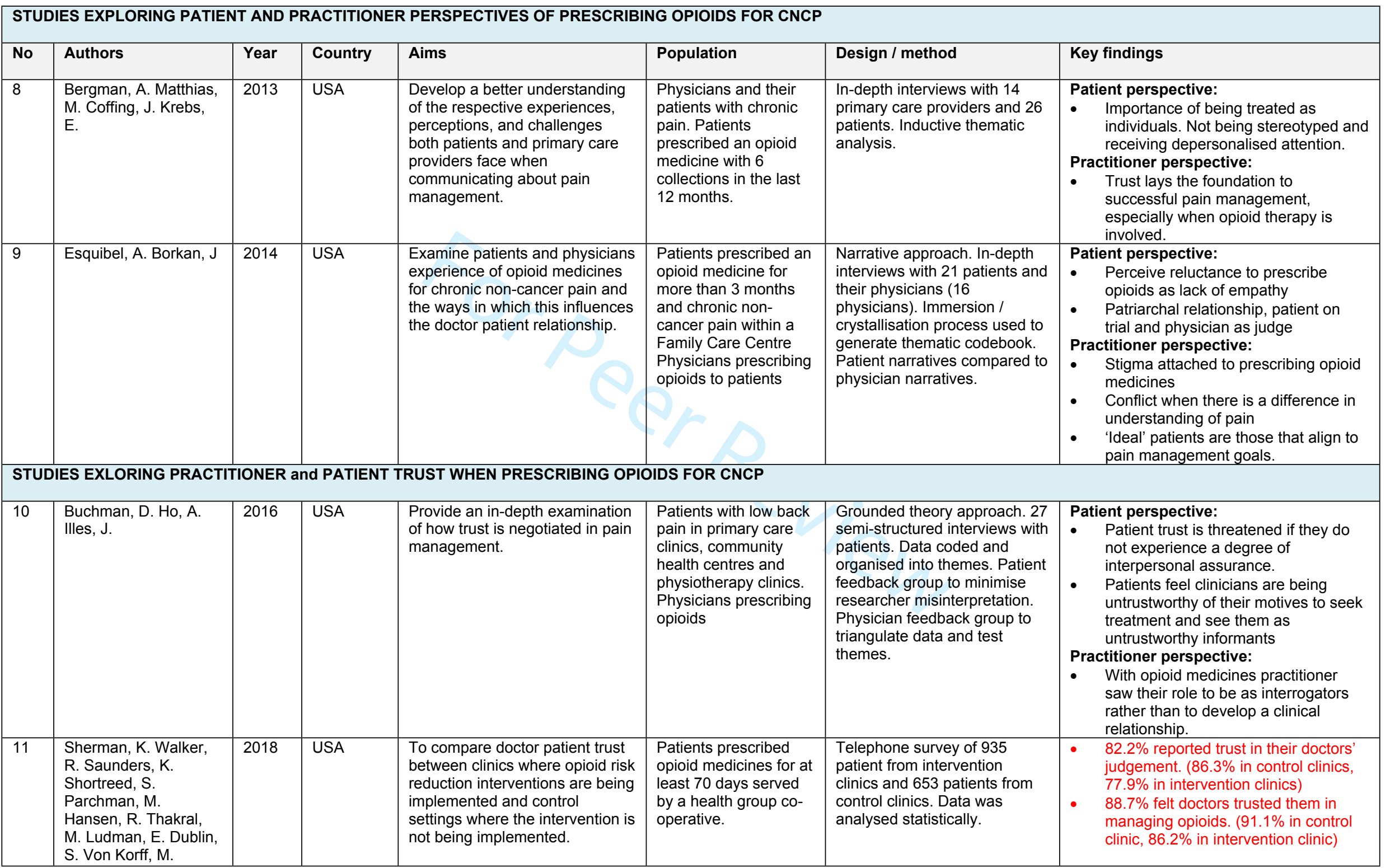




\begin{tabular}{|c|c|c|c|c|c|c|c|}
\hline No & Authors & Year & Country & Aims & Population & Design / method & Key findings \\
\hline 12 & $\begin{array}{l}\text { Matthias, M. Krebs, E. } \\
\text { Bergman, A. Coffing, } \\
\text { J. Bair, M. }\end{array}$ & 2013 & USA & $\begin{array}{l}\text { Improve understanding about } \\
\text { communication when prescribing } \\
\text { opioid medicines. Gain an } \\
\text { insight into how relationships } \\
\text { between patient and physician } \\
\text { shape communication about } \\
\text { opioids. }\end{array}$ & $\begin{array}{l}\text { Physicians and } \\
\text { patients in primary } \\
\text { care clinics. Patients } \\
\text { were prescribed opioid } \\
\text { medicines for } \\
\text { musculoskeletal pain. }\end{array}$ & $\begin{array}{l}5 \text { physicians and } 30 \text { patients } \\
\text { participated. } 30 \text { clinic visits } \\
\text { were audio recorded. } \\
\text { Individual patient interviews } \\
\text { after the consultation. } \\
\text { Immersion / crystallisation } \\
\text { approach was used to analyse } \\
\text { the data. }\end{array}$ & $\begin{array}{l}\text { Patient perspective: } \\
\text { - Some patients believed their doctors } \\
\text { did not listen to them or care about } \\
\text { their well-being. } \\
\text { Whilst other patients believed doctors } \\
\text { listened to them and had genuine } \\
\text { concern for their care. }\end{array}$ \\
\hline 13 & $\begin{array}{l}\text { Henry, S. Bell, R. } \\
\text { Fenton, J. Kravitz, R. }\end{array}$ & 2018 & USA & $\begin{array}{l}\text { To understand communication } \\
\text { between physicians and patient } \\
\text { about chronic pain and opioids. }\end{array}$ & $\begin{array}{l}\text { Patients and } \\
\text { physicians at two } \\
\text { primary care academic } \\
\text { clinics. Patients were } \\
\text { prescribed long-term } \\
\text { opioid medicines for } \\
\text { chronic } \\
\text { musculoskeletal pain. } \\
\end{array}$ & $\begin{array}{l}86 \text { patient clinic consultations } \\
\text { were videotaped, involving } 49 \\
\text { physicians. Data of patient } \\
\text { experience and physician visit } \\
\text { difficulty was also collected. } \\
\text { Data from consultations was } \\
\text { coded. Statistical analysis was } \\
\text { conducted to relate codes to } \\
\text { patient and physician } \\
\text { experience. }\end{array}$ & $\begin{array}{l}\text { Patient - physician disagreement and } \\
\text { patient request for opioid dose } \\
\text { increases were significantly } \\
\text { associated with worse patient } \\
\text { experience and physician visit } \\
\text { difficulty. } \\
\text { Visits with patients who reported a } \\
\text { greater desire for increased pain } \\
\text { medicine were significantly associated } \\
\text { with worse patient experience and } \\
\text { physician visit difficulty. }\end{array}$ \\
\hline 14 & $\begin{array}{l}\text { Matthias, M. Johnson, } \\
\text { N. Shields, C. Bair, M. } \\
\text { MacKie, P. Huffman, } \\
\text { M. Alexander, S. }\end{array}$ & 2017 & USA & $\begin{array}{l}\text { In depth examination about } \\
\text { opioid tapering to identify } \\
\text { communicative challenges and } \\
\text { best practices. }\end{array}$ & $\begin{array}{l}\text { Primary care clinics } \\
\text { serving primarily low } \\
\text { income patients. } \\
\text { Primary care } \\
\text { physicians currently } \\
\text { prescribing opioid } \\
\text { medicines. Patients } \\
\text { prescribed an opioid } \\
\text { medicine for } \\
\text { musculoskeletal pain. }\end{array}$ & $\begin{array}{l}9 \text { primary care physicians and } \\
37 \text { of their patients } \\
\text { participated. } 95 \text { clinic visits } \\
\text { were audio recorded. Patients } \\
\text { and physicians were } \\
\text { interviewed about patient - } \\
\text { provider relationship. Data } \\
\text { was analysed using constant } \\
\text { comparison. }\end{array}$ & $\begin{array}{l}\text { - Not all patients felt involved in the } \\
\text { process and did not understand why } \\
\text { their doses were being reduced. } \\
\text { Where patients think they are doing } \\
\text { well with their prescribed opioid, } \\
\text { conversations about tapering can be } \\
\text { especially difficult. } \\
\text { Unsuccessful negotiations about } \\
\text { tapering led to contention and } \\
\text { frustration } \\
\text { Ensure patients do not feel } \\
\text { abandoned in the process of tapering. }\end{array}$ \\
\hline 15 & $\begin{array}{l}\text { Henry, S. Gosdin, M. } \\
\text { White, A. Kravitz, R. }\end{array}$ & 2020 & USA & $\begin{array}{l}\text { To identify patient statements to } \\
\text { opioids that indicates potential } \\
\text { openness to tapering opioids } \\
\text { and characterise physician } \\
\text { responses to the statements. }\end{array}$ & $\begin{array}{l}\text { Primary care } \\
\text { physicians. Patients } \\
\text { with musculoskeletal } \\
\text { pain prescribed a } \\
\text { long-term opioid. }\end{array}$ & $\begin{array}{l}86 \text { clinic visits were video } \\
\text { recorded. Data was analysed } \\
\text { using coded assessment of } \\
\text { patient statements and } \\
\text { reported side effects. } \\
\text { Assessments were coded as } \\
\text { positive, negative or } \\
\text { ambivalent stance towards } \\
\text { opioids. }\end{array}$ & $\begin{array}{l}43 \% \text { of the time physicians did not respond } \\
\text { to / or had minimal response to clues } \\
\text { where opioid discontinuation may have } \\
\text { been explored. }\end{array}$ \\
\hline
\end{tabular}




\begin{tabular}{|c|c|c|c|c|c|c|c|}
\hline \multicolumn{8}{|c|}{ BETWEEN PRACTITIONERS AND PATIENTS WHEN PRESCRIBING OPIOIDS FOR CNCP } \\
\hline No & Authors & Year & Country & Aims & Population & Design / method & Key findings \\
\hline 16 & $\begin{array}{l}\text { Sheilds, C. Fuzzell, L. } \\
\text { Christ, S. Matthias, M. }\end{array}$ & 2019 & USA & $\begin{array}{l}\text { Examine primary care provider } \\
\text { and patient characteristics } \\
\text { related to discussions of pain } \\
\text { and opioid management. }\end{array}$ & $\begin{array}{l}\text { Physicians and } \\
\text { patients in primary } \\
\text { care clinics. Patients } \\
\text { were prescribed opioid } \\
\text { medicines for } \\
\text { musculoskeletal pain. }\end{array}$ & $\begin{array}{l}30 \text { patients and } 8 \text { primary care } \\
\text { physicians participated in } \\
\text { audio recording } 78 \text { primary } \\
\text { care visits. Patients and } \\
\text { physicians completed } \\
\text { questionnaires before and } \\
\text { after their first recorded visit. } \\
\text { Audio recordings were coded } \\
\text { to a list of communication } \\
\text { measures. Statistical analysis } \\
\text { to relate patient and physician } \\
\text { characteristics to } \\
\text { communication. }\end{array}$ & $\begin{array}{l}\text { Greater patient pain catastrophizing } \\
\text { and higher primary care physician } \\
\text { psychosocial orientation were } \\
\text { associated with discussion about } \\
\text { opioid and pain management. }\end{array}$ \\
\hline 17 & $\begin{array}{l}\text { Matthias, M. Talib, T. } \\
\text { Huffman, M. }\end{array}$ & 2019 & USA & $\begin{array}{l}\text { To understand treatment } \\
\text { decision making with patients } \\
\text { taking opioid medicines. }\end{array}$ & $\begin{array}{l}\text { Primary care } \\
\text { physicians in four } \\
\text { primary care clinics. } \\
\text { Patients with chronic } \\
\text { musculoskeletal pain } \\
\text { taking prescribed } \\
\text { opioid medicines. }\end{array}$ & $\begin{array}{l}95 \text { clinic visits were audio- } \\
\text { recorded. There were between } \\
37 \text { patients and } 9 \text { physicians. } \\
\text { Semi-structured interviews } \\
\text { with } 22 \text { patients and } 9 \\
\text { physicians. Constant } \\
\text { comparison was used to } \\
\text { analyse the data. }\end{array}$ & $\begin{array}{ll}\text { - } & \text { Disagreements were rooted in } \\
\text { perceptions of not being listened to } \\
\text { and distrust. }\end{array}$ \\
\hline 18 & $\begin{array}{l}\text { Buonora, M. Perez, H. } \\
\text { Stumph, J. Allen, R. } \\
\text { Nahvi, S. } \\
\text { Cummingham, C. } \\
\text { Merlin, J. Starrels, J. }\end{array}$ & 2020 & USA & $\begin{array}{l}\text { To describe clinician } \\
\text { documentation and rationale and } \\
\text { patient engagement in opioid } \\
\text { tapering decisions. }\end{array}$ & $\begin{array}{l}\text { Primary care } \\
\text { practices. Patients } \\
\text { without cancer } \\
\text { prescribed long-term } \\
\text { opioids who } \\
\text { experienced an opioid } \\
\text { taper. }\end{array}$ & $\begin{array}{l}\text { Thematic analysis of } 39 \\
\text { patient records. }\end{array}$ & $\begin{array}{l}\text { - Rationale for taper tended to focus on } \\
\text { patient behaviours } \\
\text { Documentation tended to reflect } \\
\text { practitioner view points, suggesting } \\
\text { tapers were practitioner initiated. } \\
\text { Patient disagreement with clinician } \\
\text { plan was prominent }\end{array}$ \\
\hline
\end{tabular}




\begin{tabular}{|c|c|c|c|c|c|c|c|}
\hline & & & & & & & \\
\hline \multicolumn{8}{|c|}{ STUDIES EXPLORING HOW PROBLEMATIC PRESCRIBING OF OPIOIDS FOR CNCP BECOMES ESTABLISHED } \\
\hline No & Authors & Year & Country & Aims & Population & Design / method & Key findings \\
\hline 19 & $\begin{array}{l}\text { McCrorie, C. Closs, S. } \\
\text { House, A. Petty, D. } \\
\text { Ziegler, L. Glidewell, } \\
\text { L. West, R. Foy, R. }\end{array}$ & 2015 & UK & $\begin{array}{l}\text { To understand how problematic } \\
\text { long-term opioid prescribing } \\
\text { becomes established. }\end{array}$ & $\begin{array}{l}\text { Patients and GPs } \\
\text { within GP practices. } \\
\text { Patients prescribed } \\
\text { opioid medicines for } \\
\text { chronic non-cancer } \\
\text { pain. }\end{array}$ & $\begin{array}{l}\text { Grounded theory approach. } \\
\text { Semi-structured interviews } \\
\text { with } 23 \text { patients. Prompts from } \\
\text { interviews were used to } \\
\text { facilitate focus group } \\
\text { discussions with GPs. } \\
\text { Constant comparison was } \\
\text { used to analyses data. }\end{array}$ & $\begin{array}{l}\text { Practitioner perspective: } \\
\text { - } \quad \text { Establishing trust was difficult when } \\
\text { GPs had formed fixed negative } \\
\text { attitudes towards patients. } \\
\text { - GPs anticipated problematic } \\
\quad \text { consultations with patients. } \\
\text { Patient perspective: } \\
\text { - Practitioner explanations about pain } \\
\quad \text { led to scepticism in patients }\end{array}$ \\
\hline \multicolumn{8}{|c|}{ STUDIES EXPLORING THE ACCEPTABILITY OF A PAIN MANAGEMENT SERVICE } \\
\hline 20 & $\begin{array}{l}\text { Kesten, J. Thomas, K. } \\
\text { Scott, L. Bache, K. } \\
\text { Hickman, M. } \\
\text { Campbell, R. } \\
\text { Pickering, A. } \\
\text { Redwood, S. }\end{array}$ & 2020 & UK & $\begin{array}{l}\text { Acceptability (perceived } \\
\text { appropriateness) of the South } \\
\text { Gloucestershire pain review } \\
\text { services. }\end{array}$ & $\begin{array}{l}\text { Patients and project } \\
\text { workers at the South } \\
\text { Gloucestershire pain } \\
\text { review services. }\end{array}$ & $\begin{array}{l}\text { Semi-structured interviews } \\
\text { with } 18 \text { patients, } 4 \mathrm{GPs}, 1 \\
\text { service manager and } 2 \text { project } \\
\text { workers. Inductive thematic } \\
\text { analysis of data. }\end{array}$ & $\begin{array}{l}\text { Patient perspective: } \\
\text { - Patients welcomed non-judgemental } \\
\text { and encouraging consultations. } \\
\text { - } \quad \text { Project workers described as kind and } \\
\text { good listeners. } \\
\text { Patients disliked not being present } \\
\quad \text { when their case was discussed } \\
\text { between project worker and GP. } \\
\text { Practitioner perspective: } \\
\text { - Described importance of forming } \\
\quad \text { trusting and open relationships } \\
\end{array}$ \\
\hline
\end{tabular}


Provide a structured summary that includes (as applicable): background, objectives, eligibility criteria,

2 sources of evidence, charting methods, results, and conclusions that relate to the review questions and objectives.

\section{INTRODUCTION}

Describe the rationale for the review in the context of what is already known. Explain why the review questions/objectives lend themselves to a scoping review approach.

Provide an explicit statement of the questions and objectives being addressed with reference to their key

Objectives elements (e.g., population or participants, concepts, and context) or other relevant key elements used to conceptualize the review questions and/or objectives.

\begin{tabular}{|c|c|c|c|}
\hline SECTION & ITEM & PRISMA-ScR CHECKLIST ITEM & $\begin{array}{l}\text { REPORTED } \\
\text { ON PAGE \# }\end{array}$ \\
\hline \multicolumn{4}{|l|}{ TITLE } \\
\hline Title & 1 & Identify the report as a scoping review. & 1 \\
\hline \multicolumn{4}{|l|}{ ABSTRACT } \\
\hline $\begin{array}{l}\text { Structured } \\
\text { summary }\end{array}$ & 2 & $\begin{array}{l}\text { Provide a structured summary that includes (as } \\
\text { applicable): background, objectives, eligibility criteria, } \\
\text { sources of evidence, charting methods, results, and } \\
\text { conclusions that relate to the review questions and } \\
\text { objectives. }\end{array}$ & 2 \\
\hline \multicolumn{4}{|l|}{ INTRODUCTION } \\
\hline Rationale & 3 & $\begin{array}{l}\text { Describe the rationale for the review in the context of } \\
\text { what is already known. Explain why the review } \\
\text { questions/objectives lend themselves to a scoping } \\
\text { review approach. }\end{array}$ & $3 / 4$ \\
\hline Objectives & 4 & $\begin{array}{l}\text { Provide an explicit statement of the questions and } \\
\text { objectives being addressed with reference to their key } \\
\text { elements (e.g., population or participants, concepts, and } \\
\text { context) or other relevant key elements used to } \\
\text { conceptualize the review questions and/or objectives. }\end{array}$ & $5 / 6$ \\
\hline \multicolumn{4}{|l|}{ METHODS } \\
\hline $\begin{array}{l}\text { Protocol and } \\
\text { registration }\end{array}$ & 5 & $\begin{array}{l}\text { Indicate whether a review protocol exists; state if and } \\
\text { where it can be accessed (e.g., a Web address); and if } \\
\text { available, provide registration information, including the } \\
\text { registration number. }\end{array}$ & 5, Appendix 1 \\
\hline Eligibility criteria & 6 & $\begin{array}{l}\text { Specify characteristics of the sources of evidence used } \\
\text { as eligibility criteria (e.g., years considered, language, } \\
\text { and publication status), and provide a rationale. }\end{array}$ & $5 / 6$ \\
\hline $\begin{array}{l}\text { Information } \\
\text { sources* }^{*}\end{array}$ & 7 & $\begin{array}{l}\text { Describe all information sources in the search (e.g., } \\
\text { databases with dates of coverage and contact with } \\
\text { authors to identify additional sources), as well as the } \\
\text { date the most recent search was executed. }\end{array}$ & 6 \\
\hline Search & 8 & $\begin{array}{l}\text { Present the full electronic search strategy for at least } 1 \\
\text { database, including any limits used, such that it could be } \\
\text { repeated. }\end{array}$ & Appendix 2 \\
\hline $\begin{array}{l}\text { Selection of } \\
\text { sources of } \\
\text { evidence }\end{array}$ & 9 & $\begin{array}{l}\text { State the process for selecting sources of evidence (i.e., } \\
\text { screening and eligibility) included in the scoping review. }\end{array}$ & 7 \\
\hline $\begin{array}{l}\text { Data charting } \\
\text { process } \ddagger\end{array}$ & 10 & $\begin{array}{l}\text { Describe the methods of charting data from the included } \\
\text { sources of evidence (e.g., calibrated forms or forms that } \\
\text { have been tested by the team before their use, and } \\
\text { whether data charting was done independently or in } \\
\text { duplicate) and any processes for obtaining and } \\
\text { confirming data from investigators. }\end{array}$ & 6 \\
\hline Data items & 11 & $\begin{array}{l}\text { List and define all variables for which data were sought } \\
\text { and any assumptions and simplifications made. }\end{array}$ & 6 \\
\hline $\begin{array}{l}\text { Critical appraisal of } \\
\text { individual sources } \\
\text { of evidence }\end{array}$ & 12 & $\begin{array}{l}\text { If done, provide a rationale for conducting a critical } \\
\text { appraisal of included sources of evidence; describe the } \\
\text { methods used and how this information was used in any } \\
\text { data synthesis (if appropriate). }\end{array}$ & Not done \\
\hline Synthesis of results & 13 & $\begin{array}{l}\text { Describe the methods of handling and summarizing the } \\
\text { data that were charted. }\end{array}$ & 6 \\
\hline
\end{tabular}

\section{2}

\begin{tabular}{|c|c|c|c|}
\hline SECTION & ITEM & PRISMA-ScR CHECKLIST ITEM & $\begin{array}{l}\text { REPORTED } \\
\text { ON PAGE \# }\end{array}$ \\
\hline \multicolumn{4}{|l|}{ TITLE } \\
\hline Title & 1 & Identify the report as a scoping review. & 1 \\
\hline \multicolumn{4}{|l|}{ ABSTRACT } \\
\hline $\begin{array}{l}\text { Structured } \\
\text { summary }\end{array}$ & 2 & $\begin{array}{l}\text { Provide a structured summary that includes (as } \\
\text { applicable): background, objectives, eligibility criteria, } \\
\text { sources of evidence, charting methods, results, and } \\
\text { conclusions that relate to the review questions and } \\
\text { objectives. }\end{array}$ & 2 \\
\hline \multicolumn{4}{|l|}{ INTRODUCTION } \\
\hline Rationale & 3 & $\begin{array}{l}\text { Describe the rationale for the review in the context of } \\
\text { what is already known. Explain why the review } \\
\text { questions/objectives lend themselves to a scoping } \\
\text { review approach. }\end{array}$ & $3 / 4$ \\
\hline Objectives & 4 & $\begin{array}{l}\text { Provide an explicit statement of the questions and } \\
\text { objectives being addressed with reference to their key } \\
\text { elements (e.g., population or participants, concepts, and } \\
\text { context) or other relevant key elements used to } \\
\text { conceptualize the review questions and/or objectives. }\end{array}$ & $5 / 6$ \\
\hline \multicolumn{4}{|l|}{ METHODS } \\
\hline $\begin{array}{l}\text { Protocol and } \\
\text { registration }\end{array}$ & 5 & $\begin{array}{l}\text { Indicate whether a review protocol exists; state if and } \\
\text { where it can be accessed (e.g., a Web address); and if } \\
\text { available, provide registration information, including the } \\
\text { registration number. }\end{array}$ & 5, Appendix 1 \\
\hline Eligibility criteria & 6 & $\begin{array}{l}\text { Specify characteristics of the sources of evidence used } \\
\text { as eligibility criteria (e.g., years considered, language, } \\
\text { and publication status), and provide a rationale. }\end{array}$ & $5 / 6$ \\
\hline $\begin{array}{l}\text { Information } \\
\text { sources* }^{*}\end{array}$ & 7 & $\begin{array}{l}\text { Describe all information sources in the search (e.g., } \\
\text { databases with dates of coverage and contact with } \\
\text { authors to identify additional sources), as well as the } \\
\text { date the most recent search was executed. }\end{array}$ & 6 \\
\hline Search & 8 & $\begin{array}{l}\text { Present the full electronic search strategy for at least } 1 \\
\text { database, including any limits used, such that it could be } \\
\text { repeated. }\end{array}$ & Appendix 2 \\
\hline $\begin{array}{l}\text { Selection of } \\
\text { sources of } \\
\text { evidence† }\end{array}$ & 9 & $\begin{array}{l}\text { State the process for selecting sources of evidence (i.e., } \\
\text { screening and eligibility) included in the scoping review. }\end{array}$ & 7 \\
\hline $\begin{array}{l}\text { Data charting } \\
\text { process } \neq\end{array}$ & 10 & $\begin{array}{l}\text { Describe the methods of charting data from the included } \\
\text { sources of evidence (e.g., calibrated forms or forms that } \\
\text { have been tested by the team before their use, and } \\
\text { whether data charting was done independently or in } \\
\text { duplicate) and any processes for obtaining and } \\
\text { confirming data from investigators. }\end{array}$ & 6 \\
\hline Data items & 11 & $\begin{array}{l}\text { List and define all variables for which data were sought } \\
\text { and any assumptions and simplifications made. }\end{array}$ & 6 \\
\hline $\begin{array}{l}\text { Critical appraisal of } \\
\text { individual sources } \\
\text { of evidence } \S\end{array}$ & 12 & $\begin{array}{l}\text { If done, provide a rationale for conducting a critical } \\
\text { appraisal of included sources of evidence; describe the } \\
\text { methods used and how this information was used in any } \\
\text { data synthesis (if appropriate). }\end{array}$ & Not done \\
\hline Synthesis of results & 13 & $\begin{array}{l}\text { Describe the methods of handling and summarizing the } \\
\text { data that were charted. }\end{array}$ & 6 \\
\hline
\end{tabular}

\begin{tabular}{|c|c|c|c|}
\hline SECTION & ITEM & PRISMA-ScR CHECKLIST ITEM & $\begin{array}{l}\text { REPORTED } \\
\text { ON PAGE \# }\end{array}$ \\
\hline \multicolumn{4}{|l|}{ TITLE } \\
\hline Title & 1 & Identify the report as a scoping review. & 1 \\
\hline \multicolumn{4}{|l|}{ ABSTRACT } \\
\hline $\begin{array}{l}\text { Structured } \\
\text { summary }\end{array}$ & 2 & $\begin{array}{l}\text { Provide a structured summary that includes (as } \\
\text { applicable): background, objectives, eligibility criteria, } \\
\text { sources of evidence, charting methods, results, and } \\
\text { conclusions that relate to the review questions and } \\
\text { objectives. }\end{array}$ & 2 \\
\hline \multicolumn{4}{|l|}{ INTRODUCTION } \\
\hline Rationale & 3 & $\begin{array}{l}\text { Describe the rationale for the review in the context of } \\
\text { what is already known. Explain why the review } \\
\text { questions/objectives lend themselves to a scoping } \\
\text { review approach. }\end{array}$ & $3 / 4$ \\
\hline Objectives & 4 & $\begin{array}{l}\text { Provide an explicit statement of the questions and } \\
\text { objectives being addressed with reference to their key } \\
\text { elements (e.g., population or participants, concepts, and } \\
\text { context) or other relevant key elements used to } \\
\text { conceptualize the review questions and/or objectives. }\end{array}$ & $5 / 6$ \\
\hline \multicolumn{4}{|l|}{ METHODS } \\
\hline $\begin{array}{l}\text { Protocol and } \\
\text { registration }\end{array}$ & 5 & $\begin{array}{l}\text { Indicate whether a review protocol exists; state if and } \\
\text { where it can be accessed (e.g., a Web address); and if } \\
\text { available, provide registration information, including the } \\
\text { registration number. }\end{array}$ & 5, Appendix 1 \\
\hline Eligibility criteria & 6 & $\begin{array}{l}\text { Specify characteristics of the sources of evidence used } \\
\text { as eligibility criteria (e.g., years considered, language, } \\
\text { and publication status), and provide a rationale. }\end{array}$ & $5 / 6$ \\
\hline $\begin{array}{l}\text { Information } \\
\text { sources* }^{*}\end{array}$ & 7 & $\begin{array}{l}\text { Describe all information sources in the search (e.g., } \\
\text { databases with dates of coverage and contact with } \\
\text { authors to identify additional sources), as well as the } \\
\text { date the most recent search was executed. }\end{array}$ & 6 \\
\hline Search & 8 & $\begin{array}{l}\text { Present the full electronic search strategy for at least } 1 \\
\text { database, including any limits used, such that it could be } \\
\text { repeated. }\end{array}$ & Appendix 2 \\
\hline $\begin{array}{l}\text { Selection of } \\
\text { sources of } \\
\text { evidence† }\end{array}$ & 9 & $\begin{array}{l}\text { State the process for selecting sources of evidence (i.e., } \\
\text { screening and eligibility) included in the scoping review. }\end{array}$ & 7 \\
\hline $\begin{array}{l}\text { Data charting } \\
\text { process } \neq\end{array}$ & 10 & $\begin{array}{l}\text { Describe the methods of charting data from the included } \\
\text { sources of evidence (e.g., calibrated forms or forms that } \\
\text { have been tested by the team before their use, and } \\
\text { whether data charting was done independently or in } \\
\text { duplicate) and any processes for obtaining and } \\
\text { confirming data from investigators. }\end{array}$ & 6 \\
\hline Data items & 11 & $\begin{array}{l}\text { List and define all variables for which data were sought } \\
\text { and any assumptions and simplifications made. }\end{array}$ & 6 \\
\hline $\begin{array}{l}\text { Critical appraisal of } \\
\text { individual sources } \\
\text { of evidence } \S\end{array}$ & 12 & $\begin{array}{l}\text { If done, provide a rationale for conducting a critical } \\
\text { appraisal of included sources of evidence; describe the } \\
\text { methods used and how this information was used in any } \\
\text { data synthesis (if appropriate). }\end{array}$ & Not done \\
\hline Synthesis of results & 13 & $\begin{array}{l}\text { Describe the methods of handling and summarizing the } \\
\text { data that were charted. }\end{array}$ & 6 \\
\hline
\end{tabular}

REPORTED ON PAGE \# 
Give numbers of sources of evidence screened, assessed for eligibility, and included in the review, with reasons for exclusions at each stage, ideally using a flow diagram.

15 For each source of evidence, present characteristics for which data were charted and provide the citations.

Critical appraisal within sources of evidence

16 If done, present data on critical appraisal of included sources of evidence (see item 12).

Results of individual sources

17

For each included source of evidence, present the of evidence relevant data that were charted that relate to the review questions and objectives.

Synthesis of results

18 Summarize and/or present the charting results as they relate to the review questions and objectives.

7

\section{DISCUSSION}

\begin{tabular}{|c|c|c|c|}
\hline $\begin{array}{l}\text { Summary of } \\
\text { evidence }\end{array}$ & 19 & $\begin{array}{l}\text { Summarize the main results (including an overview of } \\
\text { concepts, themes, and types of evidence available), link } \\
\text { to the review questions and objectives, and consider the } \\
\text { relevance to key groups. }\end{array}$ & 11 \\
\hline Limitations & 20 & Discuss the limitations of the scoping review process. & 12 \\
\hline Conclusions & 21 & $\begin{array}{l}\text { Provide a general interpretation of the results with } \\
\text { respect to the review questions and objectives, as well } \\
\text { as potential implications and/or next steps. }\end{array}$ & 13 \\
\hline \multicolumn{4}{|l|}{ FUNDING } \\
\hline Funding & 22 & $\begin{array}{l}\text { Describe sources of funding for the included sources of } \\
\text { evidence, as well as sources of funding for the scoping } \\
\text { review. Describe the role of the funders of the scoping } \\
\text { review. }\end{array}$ & 14 \\
\hline
\end{tabular}

$\mathrm{JBI}=$ Joanna Briggs Institute; PRISMA-ScR = Preferred Reporting Items for Systematic reviews and Meta-Analyses extension for Scoping Reviews.

* Where sources of evidence (see second footnote) are compiled from, such as bibliographic databases, social media platforms, and Web sites.

† A more inclusive/heterogeneous term used to account for the different types of evidence or data sources (e.g., review as opposed to only studies. This is not to be confused with information sources (see first footnote). $\ddagger$ The frameworks by Arksey and O'Malley (6) and Levac and coll
process of data extraction in a scoping review as data charting.

$\S$ The process of systematically examining research evidence to assess its validity, results, and relevance before using it to inform a decision. This term is used for items 12 and 19 instead of "risk of bias" (which is more applicable to systematic reviews of interventions) to include and acknowledge the various sources of evidence that may be used in a scoping review (e.g., quantitative and/or qualitative research, expert opinion, and policy document).

From: Tricco AC, Lillie E, Zarin W, O'Brien KK, Colquhoun H, Levac D, et al. PRISMA Extension for Scoping Reviews (PRISMAScR): Checklist and Explanation. Ann Intern Med. 2018;169:467-473. doi: 10.7326/M18-0850. 